\title{
Indirect radiative forcing by ion-mediated nucleation of aerosol
}

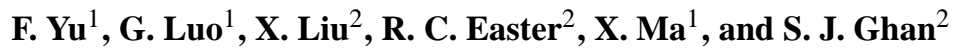 \\ ${ }^{1}$ Atmospheric Sciences Research Center, State University of New York at Albany, 251 Fuller Road, Albany, NY 12203, USA \\ ${ }^{2}$ Atmospheric Science \& Global Change Division, Pacific Northwest National Laboratory, 3200 Q Avenue, MSIN K9-24 \\ Richland, WA 99352, USA
}

Correspondence to: F. Yu (fangqun.yu@asrc.albany.edu)

Received: 13 June 2012 - Published in Atmos. Chem. Phys. Discuss.: 13 July 2012

Revised: 21 November 2012 - Accepted: 22 November 2012 - Published: 3 December 2012

\begin{abstract}
A clear understanding of particle formation mechanisms is critical for assessing aerosol indirect radiative forcing and associated climate feedback processes. Recent studies reveal the importance of ion-mediated nucleation (IMN) in generating new particles and cloud condensation nuclei $(\mathrm{CCN})$ in the atmosphere. Here we implement the IMN scheme into the Community Atmosphere Model version 5 (CAM5). Our simulations show that, compared to globally averaged results based on $\mathrm{H}_{2} \mathrm{SO}_{4}-\mathrm{H}_{2} \mathrm{O}$ binary homogeneous nucleation (BHN), the presence of ionization (i.e., IMN) halves $\mathrm{H}_{2} \mathrm{SO}_{4}$ column burden, but increases the column integrated nucleation rate by around one order of magnitude, total particle number burden by a factor of $\sim 3, \mathrm{CCN}$ burden by $\sim 10 \%$ (at $0.2 \%$ supersaturation) to $65 \%$ (at $1.0 \%$ supersaturation), and cloud droplet number burden by $\sim 18 \%$. Compared to BHN, IMN increases cloud liquid water path by $7.5 \%$, decreases precipitation by $1.1 \%$, and increases total cloud cover by $1.9 \%$. This leads to an increase of total shortwave cloud radiative forcing (SWCF) by $3.67 \mathrm{~W} \mathrm{~m}^{-2}$ (more negative) and longwave cloud forcing by $1.78 \mathrm{~W} \mathrm{~m}^{-2}$ (more positive), with large spatial variations. The effect of ionization on SWCF derived from this study $\left(3.67 \mathrm{~W} \mathrm{~m}^{-2}\right)$ is a factor of $\sim 3$ higher that of a previous study $\left(1.15 \mathrm{~W} \mathrm{~m}^{-2}\right)$ based on a different ion nucleation scheme and climate model. Based on the present CAM5 simulation, the 5-yr mean impacts of solar cycle induced changes in ionization rates on $\mathrm{CCN}$ and cloud forcing are small $\left(\sim-0.02 \mathrm{~W} \mathrm{~m}^{-2}\right)$ but have larger inter-annual (from -0.18 to $0.17 \mathrm{~W} \mathrm{~m}^{-2}$ ) and spatial variations.
\end{abstract}

\section{Introduction}

Aerosol particles formed in the atmosphere influence climate indirectly by acting as cloud condensation nuclei (CCN) that affect cloud properties and precipitation (Twomey, 1977; Albrecht, 1989). The aerosol indirect radiative forcing (IRF) is a major source of uncertainty in interpreting climate change over the past century and projecting future change. New particle formation has been well recognized to be an important source of CCN in the atmosphere (Pierce and Adams, 2007; Spracklen et al., 2008; Makkonen et al., 2009; Wang and Penner, 2009; Yu and Luo, 2009; Kazil et al., 2010). Global climate simulations indicate that the aerosol IRF is sensitive to parameterizations of nucleation processes (Wang and Penner, 2009; Kazil et al., 2010). Wang and Penner (2009) showed that the first IRF of anthropogenic aerosols (forcing due to changes in droplet number and size but not liquid water content) ranges from -1.22 to $-2.03 \mathrm{~W} \mathrm{~m}^{-2}$ for six different combinations of $\mathrm{H}_{2} \mathrm{SO}_{4}-\mathrm{H}_{2} \mathrm{O}$ binary homogeneous nucleation (BHN), empirical parameterization of boundary layer nucleation, and parameterization of primary sulfate emission to represent sub-grid scale nucleation. Kazil et al. (2010) investigated the impact of the individual aerosol nucleation mechanisms (neutral and charged nucleation of sulfuric acid throughout the troposphere, and cluster activation limited to the forested boundary layer) on the Earth's energy balance, and showed that the change in the net top of atmosphere shortwave radiative flux associated with nucleation is around $-2.55 \mathrm{~W} \mathrm{~m}^{-2}$. These previous studies highlight the importance of a clear understanding of atmospheric particle nucleation processes and proper representation of these processes in the climate models. 
There still exist large uncertainties in nucleation mechanisms, despite significant progress achieved over the past several decades (e.g., Zhang et al., 2012). One of these uncertainties is the role of air ions generated by galactic cosmic rays and radioactive materials in the nucleation process (Yu and Turco, 2000; Lovejoy et al., 2004). While the relative contribution of ion-mediated nucleation (IMN) versus neutral nucleation has been controversial in the past years (Kulmala et al., 2007; Yu and Turco, 2008), recent detailed case studies (Yu and Turco, 2011) and laboratory measurements (Enghoff et al., 2011; Kirkby et al., 2011) clearly show a significant role of ionization in promoting nucleation. In particular, Yu and Turco (2011) demonstrated that the stateof-the-art multi-instrument field measurements taken in a boreal forest appear to strongly support the dominance of IMN mechanism, which is further supported by the most recent cluster mass spectrometer measurements at the site showing the absence of small neutral clusters (Jokinen et al., 2012). It should be pointed out that empirical parameterizations of boundary layer nucleation derived from the boreal forest nucleation measurements have been widely used to represent a yet-to-be-identified mechanism of new particle formation in global models (e.g., Wang and Penner, 2009; Kazil et al., 2010) but these parameterizations could in fact be a simplified fitting to the IMN process (Yu and Turco, 2011).

Considering the unequivocal evidence of the IMN process in producing atmospheric particles, we seek to assess the effect of ionization on new particle formation, $\mathrm{CCN}$ abundance, cloud properties, and cloud radiative forcing in this study by incorporating the IMN mechanism into the Community Atmosphere Model version 5 (CAM5), the atmospheric component of the Community Earth System Model version 1 (CESM1). Our strategy is to compare results with and without the effect of ionization on new particle formation. The kinetically self-consistent $\mathrm{H}_{2} \mathrm{SO}_{4}-\mathrm{H}_{2} \mathrm{O}$ IMN is suitable for this purpose as it fully and consistently reduces to BHN when the ionization rate is zero (Yu, 2010a). The impacts of solar cycle induced changes in ionization rates on $\mathrm{CCN}$ and cloud forcing are also investigated in this study. The remaining sections of this paper are organized as follows: Model description and set-up are given in Sect. 2. Section 3 provides a detailed analysis of simulation results. Conclusions are given in Sect. 4.

\section{Model and simulation description}

The model we employed for this study is CAM5 with a modal aerosol module (MAM) using three log-normal modes (Aitken, accumulation, and coarse) to represent aerosols (MAM3). Detailed information about CAM5-MAM can be found in Liu et al. (2012). Here we give a brief summary of key features of the model relevant to the present work. In MAM3, Aitken mode species include sulfate, secondary organic aerosol (SOA), and sea salt; accumulation mode species include sulfate, SOA, black carbon (BC), primary or- ganic matter (POM), sea salt, and dust; coarse mode species include sea salt, dust, and sulfate. All species within a mode are assumed to be internally mixed. The model explicitly treats aerosol transport, primary emissions, aerosol nucleation (binary homogeneous and empirical boundary layer involving $\mathrm{H}_{2} \mathrm{SO}_{4}$ vapor), condensation of trace gases $\left(\mathrm{H}_{2} \mathrm{SO}_{4}\right.$ and semi-volatile organics) on existing aerosol particles, coagulation (Aitken and accumulation modes), dry and wet deposition, and activation into stratiform cloud droplets and resuspension (Liu et al., 2012).

The nucleated particles are grown from critical cluster size to $12 \mathrm{~nm}$ diameter and added to the Aitken mode ${ }^{1}$, with coagulation loss during their growth taken into account following the parameterization of Kerminen and Kulmala (2002). It should be noted that this approach assumes that condensational growth and coagulation conditions are constant during the growth period (typically several hours), and it applies the growth and loss in a single model time-step ${ }^{2}$ (30 min in our simulations). Actual conditions (e.g., $\mathrm{H}_{2} \mathrm{SO}_{4}$ concentration) in the atmosphere during the growth period will vary, so this approach may overpredict or underpredict the number of nucleated particles that survive during growth to larger sizes. Nevertheless, a 2 mode treatment of the sub-micron aerosol (with no nucleation mode) has been used in previous studies (e.g., Wang et al., 2009; Wang and Penner, 2009). While such a treatment appears to overestimate total particle number (Wang et al., 2009; Anttila et al., 2010), the effect on larger size particles (and CCN) is small (Wang et al., 2009) as many of the smaller Aitken mode particles are lost by coagulation. Also, growth of new particles by condensation of organics is not included in our simulations, causing an underestimation of the contribution of new particle formation to $\mathrm{CCN}$. As we will show in Sect. 3.1, the present model in general under-predicts $\mathrm{CCN}$ concentration, especially in the regions where the contributions of nucleated particles to $\mathrm{CCN}$ are expected to be significant. We note that a version of the CAM5 modal aerosol module with a nucleation mode that includes organics is under development.

Stratiform cloud microphysics is represented using the double-moment formulation of Morrison and Gettelman (2008), which predicts number and mass mixing ratios of cloud droplets and ice crystals and diagnoses number and mass mixing ratios of rain and snow particles. Autoconversion of droplets to rain depends on droplet number according to Khairoutdinov and Kogan (2000). Droplet nucleation depends on updraft velocity and the number, mean radius, and mean hygroscopicity of all aerosol modes according to

\footnotetext{
${ }^{1}$ As noted in Liu et al. (2012), the Aitken mode size range is $15-53 \mathrm{~nm}$ (based on 10th and 90th percentiles of the global annual average number distribution), and an explicit size range (or bounds) is not specified.

${ }^{2}$ The parameterization estimates the actual growth time and the coagulation loss during this time, but the result is applied in a single model time-step.
} 
Abdul-Razzak and Ghan (2000). Ice crystal nucleation depends on aerosol size distribution through both homogeneous freezing of haze particles and cloud droplets and heterogeneous freezing of cloud droplets (Liu et al., 2007); Ghan et al. (2012) showed that homogeneous nucleation in CAM5 produces a significant longwave aerosol indirect effect. Liu et al. (2007) and Gettelman et al. (2010) describe the treatment of mixed-phase cloud microphysics, including the Bergeron-Fineisen process. The present CAM5 does not consider aerosol effects on convective cloud microphysics, but does simulate aerosol wet scavenging by convective precipitation (Liu et al., 2012). The radiative transfer scheme used in CAM5 is the Rapid Radiative Transfer Model for GCMs (RRTMG), a broadband k-distribution radiation model developed for application to GCMs (e.g., Iacono et al., 2008).

In this study, we implement the IMN mechanism (Yu, 2010a) in CAM5.1. As mentioned earlier, the IMN is supported by field measurements and consistently reduces to BHN when the ionization rate is set to zero, enabling us to distinguish the effect of ionization. We run the conventional CAM5.1-MAM3 at $1.9^{\circ} \times 2.5^{\circ}$ horizontal resolution with 30 vertical levels and a time step of $30 \mathrm{~min}$, with prescribed sea surface temperature and sea ice. To study the effect of ionization, two separate simulations have been carried out under present-day climate and present-day emissions (PDPD): one with IMN and the other based on BHN (i.e., without ionization). Neither simulation uses nucleation schemes (binary homogeneous and empirical boundary layer nucleation) contained in the original version of CAM5.1. The global ionization rates due to cosmic rays are calculated based on the schemes given in Usoskin and Kovaltsov (2006), and the contribution of radioactive materials from soil to ionization rates is parameterized based on the profiles given in Reiter (1992). Sensitivity study has also been carried out to investigate the impacts of solar cycle induced changes in ionization rates on $\mathrm{CCN}$ and cloud forcing.

We use the same database and schemes for aerosol and precursor emissions (for year 2000) as described in Liu et al. (2012) and Wang et al. (2011), except that, in order to clearly assess the effect of nucleation, the fraction of anthropogenic sulfur emitted as primary sulfate (used to represent sub-grid nucleation process) has been set to zero. Many previous global aerosol modeling studies have assumed some fraction $(0-5 \%)$ of anthropogenic sulfur emitted directly as sulfate particles to account for the new particle formation in sub-grid $\mathrm{SO}_{2}$ plumes (Luo and $\mathrm{Yu}, 2011$; and references therein). However, assuming a constant fraction of sulfur emitted directly as particles (with an assumed percentage partitioning into Aitken and accumulation modes) may lead to large uncertainty in the simulated spatiotemporal distribution of particle number concentrations, owning to the strong dependence of sub-grid nucleation on many environmental parameters (especially $\mathrm{OH}$ concentration, temperature, surface area of pre-existing particles, etc.) (Yu, 2010b). In addition, treating sub-grid nucleation as primary particle emis- sion leads to underestimation of the contribution of nucleation processes to global aerosol number abundance (Luo and $\mathrm{Yu}, 2011)$. Omitting primary sulfate does not necessarily reduce the number of $\mathrm{CN}$ if a suitable nucleation scheme is used. Luo and $\mathrm{Yu}$ (2011) showed a compensation effect of nucleation to primary sulfate emission. They found that adding primary sulfate emission does not improve the agreement between simulated and observed annual mean number concentrations of particles $>10 \mathrm{~nm}$ around the globe.

We run the CAM5.1-MAM3 for 6yr (2000-2005, first year as spin-up) for two cases (i.e., with and without effect of ionization on nucleation) and results are presented in Sect. 3.1. For the case with ionization, two separate runs are carried out (Sect. 3.2), one with cosmic ray ionization rates corresponding to a solar minimum year and the other a solar maximum year.

\section{Results}

\subsection{Effect of ionization on aerosol formation and indirect forcing: BHN versus IMN}

Table 1 summarizes the globally averaged results of key variables for both BHN and IMN cases, as well as the differences for the two cases showing the impacts of ionization. To account for the differences in various altitudes, we vertically integrate all the 3-D variables to simplify the comparisons. It is clear from Table 1 that ionization has a significant effect on $\mathrm{H}_{2} \mathrm{SO}_{4}$ vapor concentrations (hereafter $\left[\mathrm{H}_{2} \mathrm{SO}_{4}\right]$ ), nucleation rates, concentrations of aerosol and $\mathrm{CCN}$, cloud properties, precipitation, shortwave cloud forcing (SWCF), and longwave cloud forcing (LWCF). The corresponding spatial distributions of selected parameters are presented in Figs. 15.

$\mathrm{H}_{2} \mathrm{SO}_{4}$ vapor from both anthropogenic (fossil fuels, etc.) and natural (DMS, volcano, etc.) sources is known to play an important role in forming and growing new particles. $\mathrm{H}_{2} \mathrm{SO}_{4}$ column burdens are high in the source and associated outflow regions (Fig. 1a-b), with highest values exceeding $6 \times 10^{16} \mathrm{~m}^{-2}$. For example, $\mathrm{H}_{2} \mathrm{SO}_{4}$ column burdens over East Asia, Europe, and Northern America are associated with anthropogenic emissions. The high $\mathrm{H}_{2} \mathrm{SO}_{4}$ burdens extending from northern Chile to northern Argentina and southern Brazil are primarily due to volcanic emissions in the Andes. $\mathrm{H}_{2} \mathrm{SO}_{4}$ vapor in the atmosphere is produced in-situ via photochemistry from anthropogenic and natural $\mathrm{SO}_{2}$, and thus have strong diurnal variations. Because of the attractive interaction between the $\mathrm{HSO}_{4}^{-}$ion and the electric dipole of $\mathrm{H}_{2} \mathrm{SO}_{4}$, IMN occurs at $\left[\mathrm{H}_{2} \mathrm{SO}_{4}\right]$ (or $\mathrm{H}_{2} \mathrm{SO}_{4}$ supersaturation ratio) lower than that needed for BHN to occur. As shown in Table 1 and Fig. 1a-b, $\mathrm{H}_{2} \mathrm{SO}_{4}$ column burden is about halved in the presence of ionization. This is mainly a result of an overall higher nucleation rate (Fig. 1c-d) and particle number concentration (Fig. 1e-f) and hence condensation 
Table 1. Globally averaged sulfuric acid vapor concentration $\left(\left[\mathrm{H}_{2} \mathrm{SO}_{4}\right]\right)$, nucleation rate $(J)$, concentrations of condensation nuclei $(\mathrm{CN})$ and cloud $\mathrm{CN}$ at water supersaturation ratio of $1.0 \%$ and $0.2 \%$ (CCN1.0, CCN0.2), cloud droplet number concentration (CDN), liquid water path (LWP), ice water path (IWP), precipitation (PRECT), total cloud cover (CLDTOT), shortwave cloud forcing (SWCF), and longwave cloud forcing (LWCF) for both BHN and IMN cases, as well as the differences for the two cases showing the impacts of ionization. To account for the differences in various altitudes, we vertically integrate all the 3-D variables to simplify the comparisons. For CCN1.0 and CCN0.2, we also give vertically integrated burden within two layers in the lower troposphere: boundary layer (BL, surface - $900 \mathrm{hPa}$ ) and middle layer (LFT, 900-650 hPa). The observed values of LWP, PRECP, CLDTOT, SWCF, and LWCF from different measurements are also given for comparisons.

\begin{tabular}{|c|c|c|c|c|c|}
\hline \multirow[b]{2}{*}{$X$} & \multirow[b]{2}{*}{$\begin{array}{r}\text { BHN } \\
X_{\mathrm{BHN}}\end{array}$} & \multirow[b]{2}{*}{$\begin{array}{r}\text { IMN } \\
X_{\text {IMN }}\end{array}$} & \multirow[b]{2}{*}{ observations } & \multicolumn{2}{|c|}{ IMN \& BHN difference } \\
\hline & & & & $\begin{array}{r}\text { Absolute } \\
X_{\mathrm{IMN}}-X_{\mathrm{BHN}}\end{array}$ & $\begin{array}{r}\text { percentage } \\
X_{\mathrm{IMN}} / X_{\mathrm{BHN}}-1\end{array}$ \\
\hline Column $\left[\mathrm{H}_{2} \mathrm{SO}_{4}\right]\left(10^{16} \# \mathrm{~m}^{-2}\right)$ & 2.80 & 1.46 & & & $-47.8 \%$ \\
\hline Column $J\left(10^{9} \# \mathrm{~m}^{-2} \mathrm{~s}^{-1}\right)$ & 0.12 & 1.26 & & & $948.7 \%$ \\
\hline Column CN $\left(10^{10} \#^{-2}\right)$ & 219.90 & 618.27 & & & $181.2 \%$ \\
\hline Column CCN1.0 $\left(10^{10} \# \mathrm{~m}^{-2}\right)$ & 129.62 & 213.22 & & & $64.5 \%$ \\
\hline CCN1.0_BL $\left(10^{10} \# \mathrm{~m}^{-2}\right)$ & 43.16 & 55.22 & & & $27.9 \%$ \\
\hline CCN1.0_LFT $\left(10^{10} \# \mathrm{~m}^{-2}\right)$ & 40.12 & 67.02 & & & $67.0 \%$ \\
\hline Column CCN0.2 $\left(10^{10} \# \mathrm{~m}^{-2}\right)$ & 55.01 & 60.15 & & & $9.3 \%$ \\
\hline CCN0.2_BL $\left(10^{10} \# \mathrm{~m}^{-2}\right)$ & 21.51 & 23.40 & & & $8.8 \%$ \\
\hline CCN0.2_LFT $\left(10^{10} \# \mathrm{~m}^{-2}\right)$ & 19.49 & 21.73 & & & $11.5 \%$ \\
\hline Column CDN $\left(10^{9} \# \mathrm{~m}^{-2}\right)$ & 13.08 & 15.46 & & & $18.3 \%$ \\
\hline $\operatorname{LWP}\left(\mathrm{g} \mathrm{m}^{-2}\right)$ & 43.81 & 47.76 & 50 to $87^{a}$ & & $9.0 \%$ \\
\hline $\operatorname{IWP}\left(\mathrm{g} \mathrm{m}^{-2}\right)$ & 17.32 & 17.95 & & & $3.6 \%$ \\
\hline PRECT $\left(\mathrm{mm} \mathrm{day}^{-1}\right)$ & 3.00 & 2.97 & $2.67^{\mathrm{b}}$ & & $-1.1 \%$ \\
\hline CLDTOT & 63.83 & 65.04 & $65.4^{\mathrm{c}}, 66.7^{\mathrm{d}}$ & & $1.9 \%$ \\
\hline $\operatorname{SWCF}\left(\mathrm{W} \mathrm{m}^{-2}\right)$ & -50.80 & -54.48 & -46 to $-53^{e}$ & $-3.68 \pm 0.10^{\mathrm{f}}$ & \\
\hline $\operatorname{LWCF}\left(\mathrm{W} \mathrm{m}^{-2}\right)$ & 23.41 & 25.19 & 27 to $31^{e}$ & $1.78 \pm 0.04^{\mathrm{f}}$ & \\
\hline
\end{tabular}

\footnotetext{
${ }^{a}$ Liquid water path is derived from SSM/I (for the years 1987-1994, Ferraro et al., 1996) and ISCCP for the year 1987 (Han et al., 1994). SSM/I data are restricted to oceans.

$\mathrm{b}$ Precipitation rate is taken from the Global Precipitation Climatology Project (GPCP) for the years 2001-2005 (Adler et al., 2003)

(http://www.gewex.org/gpcpdata).

c Total cloud cover for 2001-2005 based on MODIS data.

d Total cloud cover for 2001-2005 based on ISCCP data

e SWCF, LWCF are from ERBE for the years 1985-1989 (Kiehl and Trenberth, 1997) and CERES for the years 2000-2005 (Loeb et al., 2009).

${ }^{\mathrm{f}}$ Uncertainty is the standard error based on 5-yr of simulation.
}

sink when the effect of ions on nucleation is considered. The column integrated rate of IMN ( $J_{\text {IMN }}$, Fig. $1 \mathrm{c}$ and also Table 1) is about one order of magnitude higher than that of BHN, despite lower average $\left[\mathrm{H}_{2} \mathrm{SO}_{4}\right]$ in the IMN case. In the tropic and sub-tropic regions, areas of high nucleation generally co-locate with areas of high $\left[\mathrm{H}_{2} \mathrm{SO}_{4}\right]$. In the polar regions, nucleation is substantial over Antarctica but insignificant over Arctic regions, as a result of relatively higher $\left[\mathrm{H}_{2} \mathrm{SO}_{4}\right]$ and lower temperature over Antarctica. It should be noted that BHN can still occur even in the presence of ionization (IMN case), but its rates are much smaller than those shown in Fig. 1d because IMN lowers $\left[\mathrm{H}_{2} \mathrm{SO}_{4}\right]$ and BHN rates decrease sharply with decreasing $\left[\mathrm{H}_{2} \mathrm{SO}_{4}\right]$. Because of $\sim$ one order of magnitude higher overall nucleation rates with IMN, the total burden of condensation nuclei $(\mathrm{CN}$, calculated as the total aerosol number over all sizes/modes) for IMN cases is about tripled when compared to BHN only cases (Table 1, also Fig. 1e-f). The relatively lower enhancement in $\mathrm{CN}$ (by a factor of $\sim 3$ ) compared to that of nucle- ation rate (by a factor of $\sim 10$ ) in the presence of ionization is mainly a result of coagulation, which is enhanced in the IMN case because lower $\left[\mathrm{H}_{2} \mathrm{SO}_{4}\right]$ results in slower growth from cluster to Aitken size. Since the emissions of primary particles are the same for both IMN and BHN cases, we can see from Fig. 1e-f that IMN is a dominant source of atmospheric particles (in term of number abundance) almost everywhere except in several regions (south and east Asia, and parts of Africa and South America) where primary anthropogenic and biomass burning emissions are also significant.

Figure 2 gives the annual and zonal mean values of $\mathrm{H}_{2} \mathrm{SO}_{4}$ vapor concentration $\left(\left[\mathrm{H}_{2} \mathrm{SO}_{4}\right]\right), J$, and $\mathrm{CN}$ number concentrations for the two cases (IMN and BHN). IMN reduces $\left[\mathrm{H}_{2} \mathrm{SO}_{4}\right]$ at all altitudes and enhances $J$ and $\mathrm{CN}$ concentration at almost all altitudes except in the tropical upper troposphere above $\sim 200 \mathrm{mb}$. The larger $J$ for BHN case (compared to IMN case) in the tropical upper troposphere above $\sim 200 \mathrm{mb}$ is due to higher $\left[\mathrm{H}_{2} \mathrm{SO}_{4}\right]$ and cold temperature 

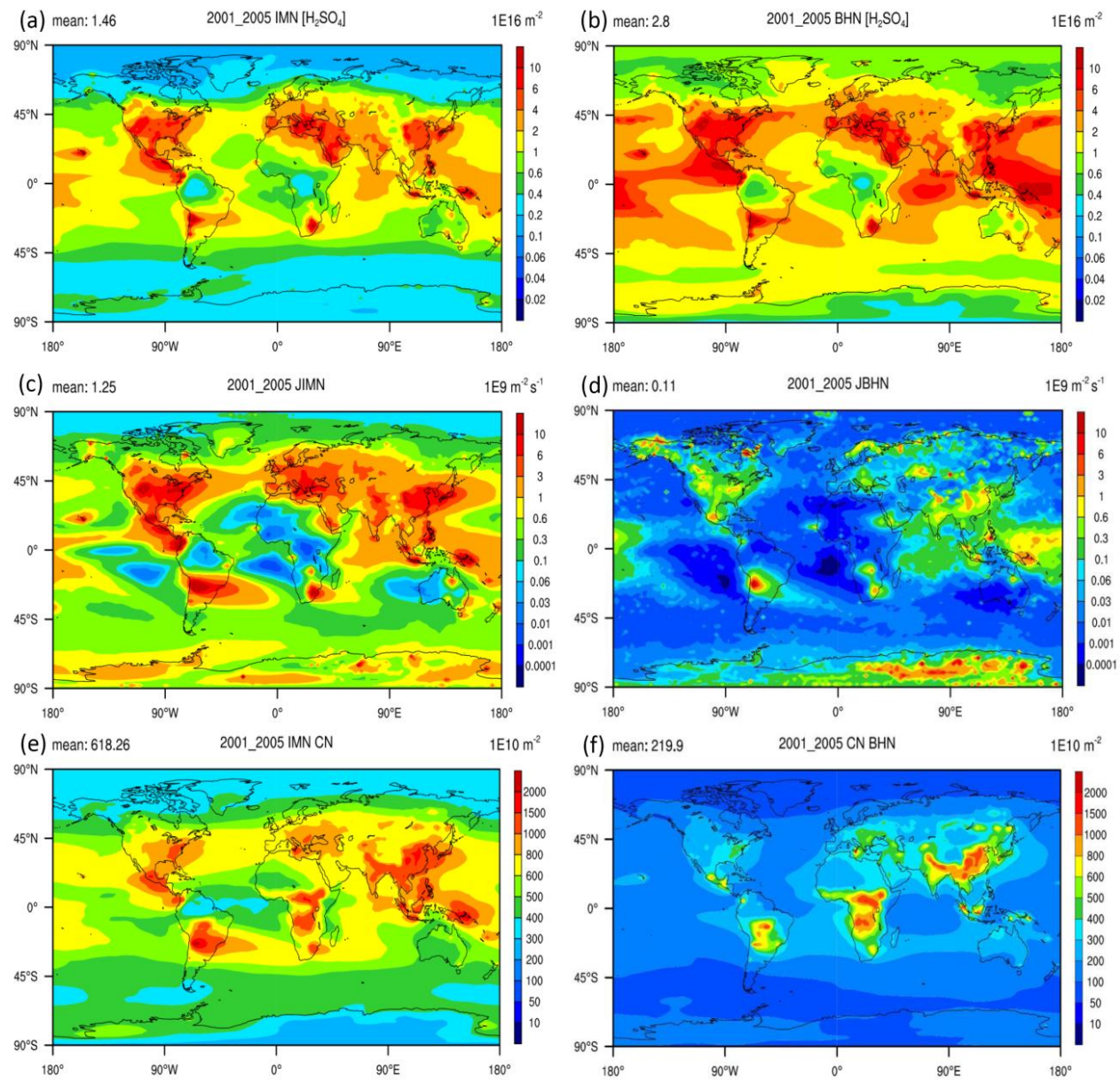

Fig. 1. Annual mean column burdens of $\mathrm{H}_{2} \mathrm{SO}_{4}$ vapor, column integrated nucleation rate $(J)$, and total condensation nuclei $(\mathrm{CN})$ number burden based on IMN (a, $\mathbf{c}, \mathbf{e})$ and $\operatorname{BHN}(\mathbf{b}, \mathbf{d}, \mathbf{f})$.

there. There exists substantial difference in the vertical distribution of $\mathrm{CN}$ concentrations for IMN and BHN cases.

In the atmosphere, the fraction of $\mathrm{CN}$ that can act as $\mathrm{CCN}$ and produce cloud droplets depends on particle size distribution and composition as well as the water supersaturations $(S)$ attained in clouds (up to $\sim 1 \%$ for convective clouds and $\sim 0.2 \%$ for stratus clouds). CCN concentration is important for aerosol indirect radiative forcing. A comparison of predicted and observed $\mathrm{CCN}$ concentrations at a water supersaturation of $0.4 \%$ (CCNO.4) is given in Fig. 3. Figure 3a shows the horizontal distribution of CCN0.4 averaged within the lower boundary layer (LBL, within $\sim 0.4 \mathrm{~km}$ above surface) predicted by CAM5-MAM3 with IMN scheme and the locations of 26 sites where CCN0.4 measurements are available. Modeled [CCN0.4] LBL has the lowest value $\left(<50 \mathrm{~cm}^{-3}\right)$ over polar regions and highest value $\left(>3000 \mathrm{~cm}^{-3}\right)$ over east Asia. [CCN0.4] LBL is generally below $\sim 200 \mathrm{~cm}^{-3}$ over remote oceans but exceeds $500 \mathrm{~cm}^{-3}$ over a large fraction of main continents. Figure $3 \mathrm{~b}$ shows that, overall, the simulations capture the horizontal variations of the observed
[CCN0.4 $]_{\text {LBL }}$ at the 26 sites worldwide, with a correlation coefficient $(r)$ of 0.76 for IMN case and 0.74 for BHN case. CAM5-MAM3 appears to under-predict [CCN0.4 $]_{\text {LBL }}$ with a normalized mean bias (NMB) of $-21 \%$ and $-28 \%$ respectively for IMN and BHN cases. The under-prediction is significant over a number of sites in Europe, especially over the boreal forest (sites C, D, E, F, G), which may be associated with the contribution of low volatile secondary organics to particle growth that is not well represented in the model. It can be seen from Fig. 3b that, compared to BHN, IMN substantially increases [CCNO.4 $]_{\text {LBL }}$ over many sites, bringing the modeled values closer to observations.

Based on the predicted 5-yr average vertically integrated CCN concentrations (or CCN burdens) at $S=1 \%$ (CCN1.0), and $S=0.2 \%(\mathrm{CCN} 0.2)$ as well as cloud droplet number $(\mathrm{CDN})$ concentrations given in Table 1, ionization enhances CCN1.0 by $64.5 \%, \mathrm{CCN} 0.2$ by $9.3 \%$, and CDN by $\sim 18.3 \%$. As expected, enhanced nucleation has a stronger effect on the concentrations of smaller particles (and hence $\mathrm{CCN}$ at higher $S$ ). In Table 1 we also give vertically 

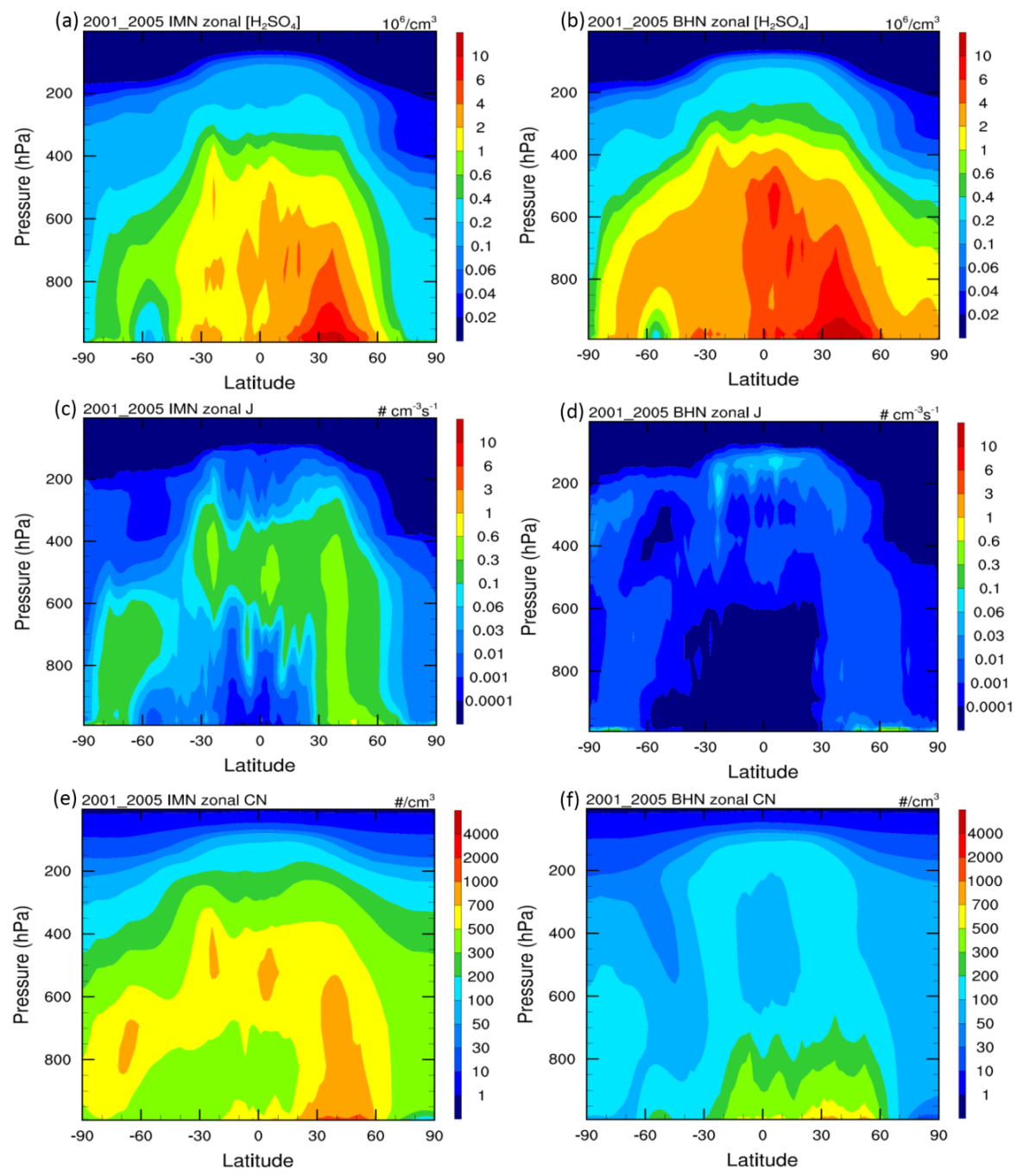

Fig. 2. Annual mean zonally averaged values of $\mathrm{H}_{2} \mathrm{SO}_{4}$ vapor concentration, nucleation rate $(J)$, and total condensation nuclei $(\mathrm{CN})$ number concentrations based on IMN (a, c, e) and $\operatorname{BHN}(\mathbf{b}, \mathbf{d}, \mathbf{f})$.

integrated CCN1.0 and CCN0.2 burden within two layers in the lower troposphere: boundary layer (BL, surface $900 \mathrm{hPa}$ ) and lower free troposphere (LFT 900-650 hPa). We can see that a large fraction of $\mathrm{CCN}$ resides in the lower troposphere (below $\sim 650 \mathrm{hPa}$ ) and the effect of ionization is larger in LFT than in BL, as a result of primary particle emission in BL and higher growth rates of nucleated particles in the lower troposphere.

Through the aerosol indirect effects (Twomey, 1977; Albrecht, 1989), the changes of CCN and CDN concentrations lead to the modification of cloud liquid water path (LWP), cloud ice water path (IWP), precipitation, and total cloud cover (CLDTOT). Compared to BHN, IMN increases LWP by $7.5 \%$, decreases precipitation by $1.1 \%$, and increases CLDTOT by $1.9 \%$ (Table 1). These percentage changes are globally averaged values and, because of various feedbacks, there exist large spatial variations of such changes. Figure 4 shows the horizontal distribution of CLDTOT and precipitation based on IMN and the differences of these two variables between IMN and BHN cases. The CLDTOT derived from MODIS and precipitation from the Global Precipitation Climatology Project (GPCP) for the same 5-yr periods are also shown for comparison. As seen in Fig. 4, the model simulations reasonably capture the spatial distribution of observed CLDTOT and precipitation. It is clear that the effect of nucleation on CLDTOT and precipitation is spatially inhomogeneous and can be both positive and negative depending on locations. The largest increase in CLDTOT associated with IMN appears to occur in the tropical and Arctic regions reaching 4-8\%.

While CAM5 captures the global distributions of total cloud cover quite well (within a few percentages for globally averaged values), there exist substantial differences between the predicted and observed global mean LWP and 

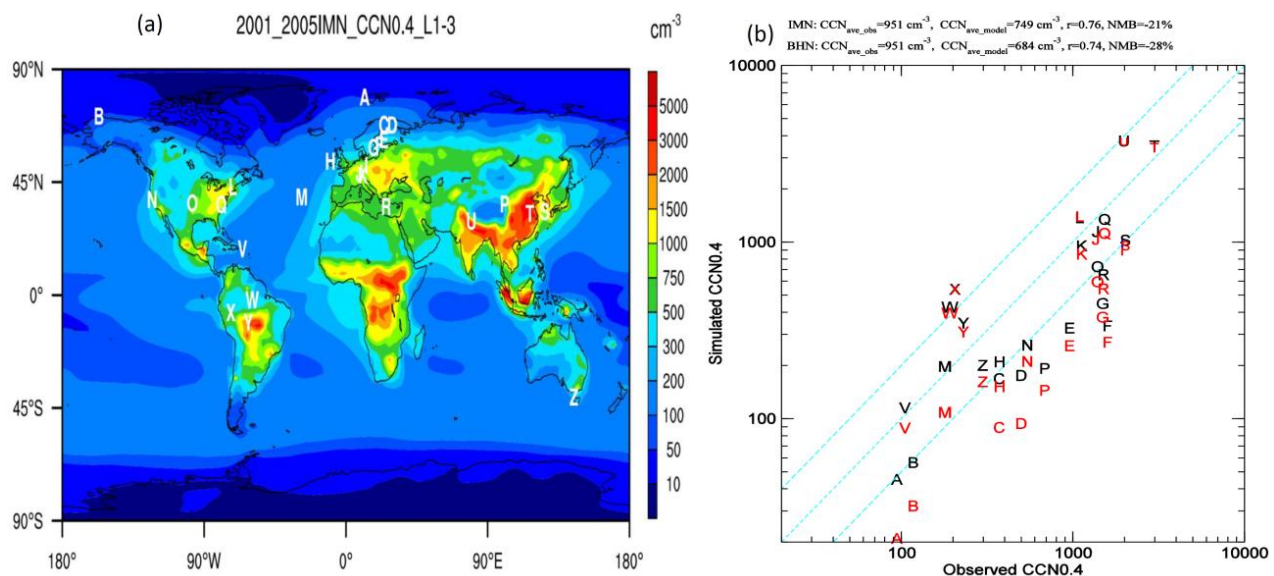

Fig. 3. (a) Horizontal distribution of the 5-yr mean number concentrations of CCN (defined at a water supersaturation of $0.4 \%-\mathrm{CCN} 0.4$ ) averaged within the lower boundary layer $(0-\sim 0.4 \mathrm{~km})\left([\mathrm{CCN} 0.4]_{\mathrm{LBL}}\right)$, as predicted by CAM5-MAM3 with IMN scheme. (b) Comparison of simulated [CCN0.4 $]_{\text {LBL }}$ based on both IMN (black letters) and BHN (red letters) schemes with observed values at 26 sites around the globe (locations are indicated in Fig. 3a by the letters). In (b), model results correspond to the months of the observations. The CCN0.4 data include those compiled by Andreae (2009) and additional data points from recent publications as well as archival observations as described in Yu et al. (2011).

precipitation $(\sim 10 \%)$ (Table 1$)$. CAM5 appears to underpredict LWP and over-predict precipitation. It should be noted that there exist large uncertainties in the observed LWP; estimates from different satellites can differ by up to $\sim 45 \%$ or more (e.g., O'Dell et al., 2008; Seethala and Horváth, 2010). In contrast, the uncertainty in precipitation data, derived from the GPCP through a merged analysis that incorporates precipitation estimates from low-orbit satellite microwave data, geosynchronous-orbit satellite infrared data, and surface rain gauge observations, is expected to be relatively smaller (uncertainty $\sim 16 \%$ ) (Adler et al., 2003). It is conceivable that the under-prediction of LWP is a result of precipitation over-prediction which occurs largely over the tropical regions (see Fig. $4 \mathrm{~d}$ and e). As mentioned earlier, the present CAM5 does not consider effects of aerosols on convective clouds which dominate precipitation volume amount. Some of the LWP and precipitation biases can also result from the representations of other physical processes such as cloud microphysics, macrophysics, and convection. Further research is needed to understand the interaction of aerosols with convective clouds and improve the representation of such interaction in CAM5.

Due to the large role of clouds in Earth's climate (total SWCF and LWCF in the order of $\sim-50 \mathrm{~W} \mathrm{~m}^{-2}$ and $25 \mathrm{~W} \mathrm{~m}^{-2}$, respectively, see Table 1 and Fig. 5), a small change in cloud properties can have substantial impacts on Earth's energy balance. Compared to the case without ionization (i.e. BHN), IMN induced changes in $\mathrm{CN}$ and CCN concentrations and thus on the LWP, precipitation, and CLDTOT increase the total SWCF by $\sim 3.67 \pm 0.10 \mathrm{~W} \mathrm{~m}^{-2}$ (more negative) and LWCF by $1.78 \pm 0.04 \mathrm{~W} \mathrm{~m}^{-2}$ (more positive). The effect of ionization on net cloud forc- ing is $-1.9 \pm 0.07 \mathrm{~W} \mathrm{~m}^{-2}$. A close look at the horizontal distributions (Fig. 5) reveals large spatial variations ranging from $\sim-20 \mathrm{~W} \mathrm{~m}^{-2}$ to $+10 \mathrm{~W} \mathrm{~m}^{-2}$ for $\triangle \mathrm{SWCF}$, and $\sim-5 \mathrm{~W} \mathrm{~m}^{-2}$ to $+20 \mathrm{~W} \mathrm{~m}^{-2}$ for $\triangle$ LWCF. $\triangle \mathrm{SWCF}$ ( $\triangle \mathrm{LWCF}$ ) is negative (positive) over most part of oceans but is positive (negative) over some part of continents. The large sensitivity of SWCF to CCN and secondary particle formation highlights the importance of reducing uncertainty in predicting key processes controlling $\mathrm{CCN}$ abundance in the troposphere. Kazil et al. (2010) investigated the globally averaged annual mean contributions of the individual nucleation processes to changes in net top-of-atmosphere shortwave radiation and showed that the contribution of charged $\mathrm{H}_{2} \mathrm{SO}_{4} / \mathrm{H}_{2} \mathrm{O}$ nucleation is $-1.15 \mathrm{~W} \mathrm{~m}^{-2}$. This value is much smaller than the $\triangle \mathrm{SWCF}$ value of $-3.67 \mathrm{~W} \mathrm{~m}^{-2}$ derived from this study. One possible reason for the difference is that the IMN used in this study (Yu, 2010a) is different from the ion-induced nucleation (IIN) (Lovejoy et al., 2004; Kazil and Lovejoy, 2007) used in Kazil et al. (2010). Previous comparisons (Yu and Turco, 2008; Yu et al., 2010) indicate that IIN rates based on the model of Lovejoy et al. (2004) are generally several orders of magnitude lower than the IMN rates and appears to under-predict the new particle formation rate in the troposphere. Another possible factor is that aerosol indirect effects in CAM5 are quite strong (Wang et al., 2011), which affects the magnitude of the IMN induced effects found in our study. Such a large difference in the impact of nucleation schemes on cloud forcing once again calls for a reduction of the uncertainty in modeling particle formation and growth processes as well as aerosol-cloud interactions in climate models. 

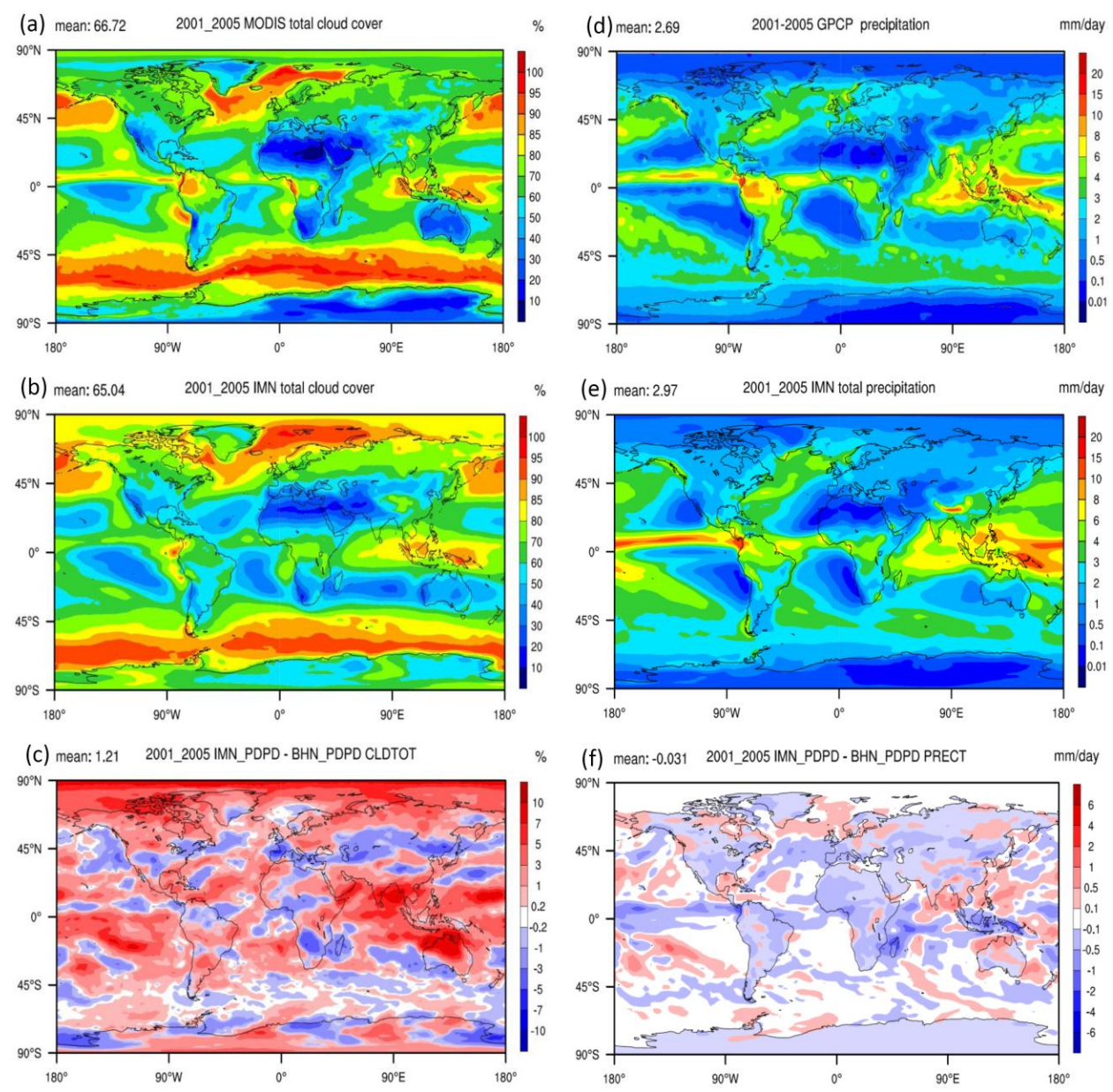

Fig. 4. Horizontal distribution of total cloud cover (CLDTOT) and precipitation rate based on IMN and the corresponding differences between IMN and BHN cases (IMN - BHN). The total CLDTOT derived from MODIS and precipitation from the Global Precipitation Climatology Project (GPCP) for the same 5-yr periods are also shown for comparison.

It should be pointed out that the dynamics in runs with different aerosol nucleation schemes can be different, which may enhance or dampen the impacts of ionization on aerosol and cloud properties. It is hard to isolate the side effect of dynamic change in climate models such as CAM5. In the model simulations reported here we are using the prescribed sea surface temperatures between different simulations. This eliminates the "slow" responses of the climate system through airsea interactions due to the aerosol perturbations but does not remove all the dynamics responses. The shortwave and longwave cloud forcing changes due to different aerosol nucleation levels reported in this paper include aerosol 1 st and 2 nd indirect effects and semi-direct effect of absorbing aerosols. Although it is difficult to separate dynamical effects from microphysical effects on cloud cover, Ghan et al. (2012) separate aerosol semi-direct effects from microphysical effects on shortwave cloud cover (which depends on liquid water path as well as cloud fraction), and find that semi-direct effects are small.
Without a data assimilation procedure such as nudging (Kooperman et al., 2012), different dynamics between two simulations can also arise because of internal variability of the model. From our previous experiences with CAM5 with prescribed sea surface temperatures, the indirect effect from the $5 \mathrm{yr}$ of simulations are very similar to that from the $10 \mathrm{yr}$ of simulations (the global mean difference is less than $0.1 \mathrm{~W} \mathrm{~m}^{-2}$ ). Ghan et al. (2012) find the standard error based on $5 \mathrm{yr}$ of simulation in the global mean aerosol indirect effect to be about $0.1 \mathrm{~W} \mathrm{~m}^{-2}$, which is far smaller than the shortwave cloud forcing signal estimated in this study. Based on 5-yr of simulation reported here, we obtain similar values of standard error $\left(0.1 \mathrm{~W} \mathrm{~m}^{-2}\right.$ for SWCF and 0.04 for $\mathrm{W} \mathrm{m}^{-2}$ for LWCF, Table 1). 

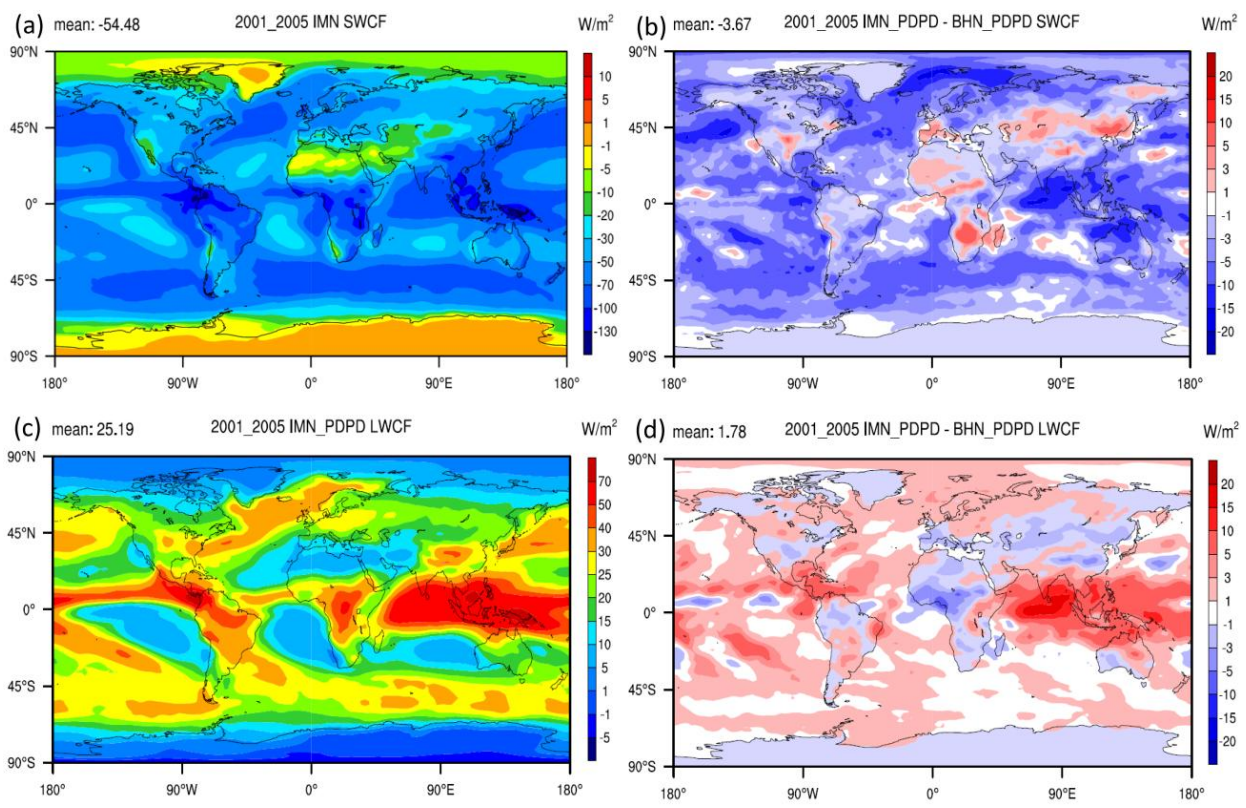

Fig. 5. Horizontal distribution of total SWCF and LWCF based on IMN and the corresponding differences between IMN and BHN cases.

\subsection{Effect of solar cycle on aerosol indirect forcing: solar minimum versus solar maximum}

The significant role of ionization in modifying global aerosol formation, $\mathrm{CCN}$ abundance, cloud properties, and cloud radiative forcing may provide an important physical mechanism linking climate change to various processes affecting atmospheric ionization (such as solar variations, Earth's magnetic field change, nuclear activities, etc.). Several previous modeling studies (Pierce and Adams, 2009; SnowKropla et al., 2011; Kazil et al., 2012) suggest small impacts of solar variation induced modulation of galactic cosmic ray (GCR) flux on aerosols and clouds. To estimate the magnitude of this indirect solar forcing, we perform two CAM5 simulations with the IMN scheme (2000-2005, first year as spin-up): one with the GCR ionization rates $(Q)$ corresponding to a solar minimum year 1996 (maximum $Q: \max Q$ ) and the other for solar maximum year 1989 (minimum $Q$ : $\min Q$ ) (Usoskin and Kovaltsov, 2006). All input parameters are same for the two simulations except annual mean $Q$ of 1996 is used for $\max Q$ case and that of 1989 is used for $\min Q$ case. The contribution of radioactive materials from soil to ionization rates is the same for both simulations.

The impacts of $Q$ changes from solar maximum $(\min Q)$ to solar minimum $(\max Q)$ on particle and cloud properties as well as cloud forcing are given in Fig. 6 and Table 2 . From $\min Q$ year to $\max Q$ year, the increase of $Q$ ranges from $\sim 5 \%$ in the tropical BL to $\sim 15 \%$ in the BL at high altitudes and up to $\sim 30 \%$ in the upper troposphere (Usoskin and Kovaltsov, 2006). Based on the CAM5 simulations, such an increase in $Q$ enhances column integrated IMN rates in a large part of troposphere (Fig. 6a), with global average enhancement of $\sim 8 \%$ (Table 2). The associated increase in the global mean burdens of $\mathrm{CN}, \mathrm{CCN} 1.0$, and $\mathrm{CCN} 0.2$ are $1.33 \times 10^{10}, 0.54 \times 10^{10}$, and $0.2 \times 10^{10} \mathrm{~m}^{-2}$, respectively (Fig. 6b-d). The level of $\mathrm{CN}$ and $\mathrm{CCN}$ burden increase in terms of percentage change is small $(0.22-0.35 \%$, Table 2$)$, which is much less than that of column integrated IMN rates. The dampened perturbation of $\mathrm{CCN}$ is likely a result of coagulation and competition for condensable gases as well as the effect of perturbed meteorology on aerosol formation and scavenging. It should be noted that while the absolute difference of particle number concentration decreases with increasing particle size (Fig. 6b-d), the 5-yr percentage change of $\mathrm{CN}$ is smaller than that of CCN (Table 2) which is surprising as the signal of solar cycle perturbation is expected to decrease with particles of increasing sizes. A further analysis for individual years (Table 2) reveals that changes of particle and cloud properties have large inter-annual variations and do not always follow a pattern expected from aerosol indirect impacts (i.e., more $\mathrm{CN} \rightarrow$ more $\mathrm{CCN} \rightarrow$ more $\mathrm{CDN}$ $\rightarrow$ reduced precipitation $\rightarrow$ enhanced CWP and CLDTOT $\rightarrow$ cooling, such as the one shown in Table 1). For example, the magnitude of $\mathrm{CDN}$ percentage change is much bigger than that of CCN0.2 in 2001 and 2003, with opposite sign in 2003. The sign of CCN1.0 and CCN0.2 percentage changes also have opposite sign in 2001, 2003, and 2005. There are several possible reasons for this: (1) internal variations of climate model that are much larger than the solar cycle signal; (2) impacts of perturbed meteorology (such as cloud cover and precipitation) on the formation and lifetime of particles; 
Table 2. The impacts of ionization rate $(Q)$ changes from solar maximum (min $Q)$ to solar minimum (max $Q$ ) on globally averaged particle and cloud properties as well as cloud forcing $(\mathrm{CF})$. The uncertainty provided with each 5-yr mean value is the standard error based on 5-yr of simulation.

\begin{tabular}{|c|c|c|c|c|c|c|c|c|c|c|c|c|}
\hline \multirow[b]{2}{*}{$X$} & \multicolumn{9}{|c|}{$\begin{array}{c}\text { Percentage change }(\%) \\
100 \cdot\left(X_{\max Q}-X_{\min Q}\right) / X_{\min Q}\end{array}$} & \multicolumn{3}{|c|}{$\begin{array}{c}\text { CF absolute change }\left(\mathrm{W} \mathrm{m}^{-2}\right) \\
X_{\max Q}-X_{\min Q}\end{array}$} \\
\hline & {$\left[\mathrm{H}_{2} \mathrm{SO}_{4}\right]$} & $J$ & $\mathrm{CN}$ & CCN1.0 & $\mathrm{CCN} 0.2$ & $\mathrm{CDN}$ & CWP & PRECT & CDLTOT & SWCF & LWCF & tot $\mathrm{CF}$ \\
\hline 2001 & -0.04 & 8.58 & 0.69 & 0.20 & -0.49 & -2.56 & -0.93 & -0.09 & -0.32 & 0.056 & 0.055 & 0.111 \\
\hline 2002 & 0.40 & 6.74 & -0.23 & 0.34 & 0.60 & -0.93 & -0.30 & -0.14 & 0.79 & -0.101 & 0.035 & -0.066 \\
\hline 2003 & -0.19 & 9.58 & 0.48 & 0.08 & -0.80 & 2.35 & 1.21 & -0.16 & 1.01 & -0.296 & 0.116 & -0.180 \\
\hline 2004 & 0.26 & 8.98 & 0.07 & 0.71 & 1.56 & 0.04 & -0.24 & -0.08 & 0.63 & -0.042 & -0.104 & -0.145 \\
\hline 2005 & -0.04 & 6.44 & 0.07 & -0.06 & 0.89 & 0.14 & -0.47 & 0.07 & 0.01 & 0.243 & -0.072 & 0.171 \\
\hline $\begin{array}{l}5-y r \\
\text { mean }\end{array}$ & $\begin{array}{r}0.08 \\
\pm 0.10\end{array}$ & $\begin{array}{r}8.06 \\
\pm 0.56\end{array}$ & $\begin{array}{r}0.22 \\
\pm 0.15\end{array}$ & $\begin{array}{r}0.26 \\
\pm 0.12\end{array}$ & $\begin{array}{r}0.35 \\
\pm 0.39\end{array}$ & $\begin{array}{l}-0.19 \\
\pm 0.72\end{array}$ & $\begin{array}{l}-0.15 \\
\pm 0.32\end{array}$ & $\begin{array}{l}-0.08 \\
\pm 0.04\end{array}$ & $\begin{array}{r}0.42 \\
\pm 0.22\end{array}$ & $\begin{array}{l}-0.028 \\
\pm 0.079\end{array}$ & $\begin{array}{r}0.006 \\
\pm 0.037\end{array}$ & $\begin{array}{l}-0.022 \\
\pm 0.062\end{array}$ \\
\hline
\end{tabular}
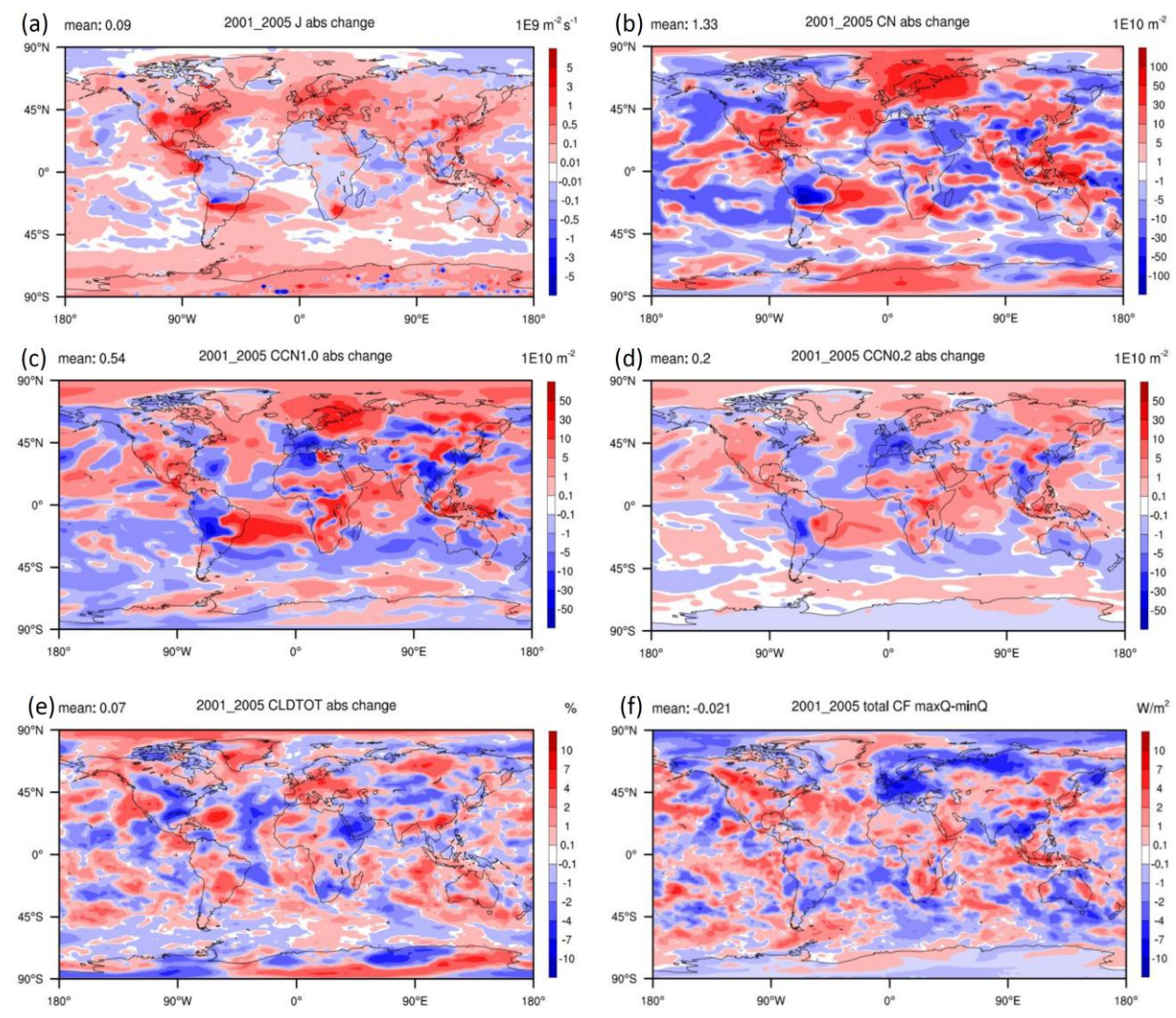

Fig. 6. Horizontal distribution of 5 -yr mean differences between $\max Q$ and $\min Q$ cases $(\max Q-\min Q)$ for column integrated (a) $J$, (b) $\mathrm{CN}$, (c) CCN1.0, and (d) CCN0.2 as well as for (e) total cloud cover and (f) net cloud forcing changes.

and (3) uncertainties in the representation of aerosol microphysics and aerosol-cloud interactions in the model.

Based on 5-yr average results, the enhancement of $\mathrm{CCN}$ associated with the change in ionization rate corresponding to a typical solar cycle (from $\min Q$ year to $\max Q$ year) slightly decreases precipitation $(-0.08 \%)$ and increases total cloud cover $(0.42 \%)$, leading to a net cloud forcing change of $-0.02 \mathrm{~W} \mathrm{~m}^{-2}$ which is not statistically significant (i.e., less than climate noise). Similar to particle and cloud properties, the changes in cloud forcing have large inter-annual variations (from $-0.18 \mathrm{~W} \mathrm{~m}^{-2}$ to $0.17 \mathrm{~W} \mathrm{~m}^{-2}$, Table 2) and spatial variations $\left(-2 \mathrm{~W} \mathrm{~m}^{-2}\right.$ to $2 \mathrm{~W} \mathrm{~m}^{-2}$ in most areas, Fig. 2). It appears that positive and negative perturbations cancel each other and the underlying mechanism of such 
cancellation is unclear. The inter-annual variability of the cloud forcing associated with solar cycles, which can be seen from the values of the standard error given in Table 2 (i.e., SWCF: $\pm 0.079 \mathrm{~W} \mathrm{~m}^{-2}$; LWCF: $\pm 0.037 \mathrm{~W} \mathrm{~m}^{-2}$ ), is smaller than the model inter-annual variability for a single simulation (see Table 1, SWCF: $\pm 0.10 \mathrm{~W} \mathrm{~m}^{-2}$; LWCF: $\pm 0.04 \mathrm{~W} \mathrm{~m}^{-2}$ ). Further research with much longer simulations as well as improved representation of particle formation and growth process is needed to assess the impact of model internal variations and uncertainties on the solar cycle signals.

\section{Summary and discussion}

Nucleation is widely known as an important source of atmospheric particles which are important to the Earth's climate through aerosol-cloud-precipitation-climate interactions. Recent detailed analysis of field studies and laboratory measurements clearly show significant impact of ionization in promoting nucleation. In the present work, based on the simulations of CAM5 with physics-based IMN mechanism incorporated, we show that ionization has a significant effect on $\mathrm{H}_{2} \mathrm{SO}_{4}$ vapor concentrations, nucleation rates, concentrations of aerosol and CCN, cloud properties, precipitation, and cloud forcing. Compared to the modeling results based on binary homogeneous nucleation (i.e., BHN case), the presence of ionization (i.e., IMN) increases the total SWCF by $\sim 3.67 \pm 0.10 \mathrm{~W} \mathrm{~m}^{-2}$ (more negative) and LWCF by $1.78 \pm 0.04 \mathrm{~W} \mathrm{~m}^{-2}$ (more positive). The effect of ionization on SWCF derived from this study $\left(3.67 \mathrm{~W} \mathrm{~m}^{-2}\right)$ is a factor of $\sim 3$ higher than that of a previous study $\left(1.15 \mathrm{~W} \mathrm{~m}^{-2}\right)$ based on a different ion nucleation scheme and climate model (Kazil et al., 2010). The large sensitivity of cloud forcing to nucleation process highlights the importance of reducing uncertainty in nucleation mechanisms and improving representation of aerosol-cloud-climate interaction processes in climate models.

It should be pointed out that the present study on the impact of ionization is based on homogeneous and ionmediated binary $\mathrm{H}_{2} \mathrm{SO}_{4}-\mathrm{H}_{2} \mathrm{O}$ nucleation. Species other than $\mathrm{H}_{2} \mathrm{SO}_{4}$ and $\mathrm{H}_{2} \mathrm{O}$ (such as ammonia, amines, organics) may influence both BHN and IMN and thus the net impact of ionization. Further research is needed to develop sound ternary homogeneous and ion-mediated nucleation theories and assess their effects on atmospheric particle formation and aerosol indirect radiative forcing. If ternary homogeneous nucleation without ions can occur at significant rates in the lower troposphere as suggested by some laboratory chamber studies (i.e., Kirkby et al., 2011), this study may substantially over-predict the impact of ionization. Nevertheless, as mentioned earlier in the introduction, so far the measurements of overcharging ratios and concentrations of small neutral clusters appear to indicate that neutral nucleation is not important at least in the boreal forest where ammonia concentration is generally well above $100 \mathrm{ppt}$ and concentrations of condensable organics are known to be high. Further studies are needed to clearly understand the relative contribution of neutral versus ion-mediated nucleation to particle abundance in the atmosphere.

The significant role of ionization in modifying global aerosol properties and cloud forcing may provide an important physical mechanism linking climate change to various processes affecting atmospheric ionization. To quantify the magnitude of solar indirect climate forcing, we carry out two runs with IMN scheme: one with the GCR ionization rates corresponding to a solar minimum year and the other to a solar maximum year. Based on the present CAM5 simulation, the 5-yr mean impacts of solar cycle induced changes in ionization rates on $\mathrm{CCN}$ and cloud forcing are small but have larger inter-annual and spatial variations. Further research is needed to assess the effect of model internal variations and uncertainties on the solar cycle signals.

Acknowledgements. This work is supported by NASA under grant NNX11AQ72G, DOE under grant DE-SC0002199 and NSF under grant 0942106 . X. Liu, R. Easter and S. Ghan, were funded by the U.S. Department of Energy, Office of Science, Scientific Discovery through Advanced Computing (SciDAC) Program and by the Office of Science Earth System Modeling Program. The Pacific Northwest National Laboratory is operated for DOE by Battelle Memorial Institute under contract DE-AC06-76RLO 1830.

Edited by: J. Quaas

\section{References}

Abdul-Razzak, H. and Ghan, S. J.: A parameterization of aerosol activation 2. Multiple aerosol types, J. Geophys. Res.-Atmos., 105, 6837-6844, 2000.

Adler, R. F., Huffman, G. J., Chang, A., Ferraro, R., Xie, P.-P., Janowiak, J., Rudolf, B., Schneider, U., Curtis, S., Bolvin, D., Gruber, A., Susskind, J., Arkin, P., and Nelkin, E.: The version-2 Global Precipitation Climatology Project (GPCP) monthly precipitation analysis (1979-present), J. Hydrometeorol., 4, 11471167, 2003.

Albrecht, B. A.: Aerosols, cloud microphysics and fractional cloudiness, Science, 245, 1227-1230, doi:10.1126/science.245.4923.1227, 1989.

Andreae, M. O.: Correlation between cloud condensation nuclei concentration and aerosol optical thickness in remote and polluted regions, Atmos. Chem. Phys., 9, 543-556, doi:10.5194/acp-9-543-2009, 2009.

Anttila, T., Kerminen, V.-M., and Lehtinen, K. E. J.: Parameterizing the formation rate of new particles: The effect of nuclei selfcoagulation, J. Aerosol Sci., 41, 621-636, 2010.

Enghoff, M. B., Pedersen, J. O. P., Uggerhøj, U. I., Paling, S. M., and Svensmark, H.: Aerosol nucleation induced by a high energy particle beam, Geophys. Res. Lett., 38, L09805, doi:10.1029/2011GL047036, 2011.

Ferraro, R. R., Weng, F. Z., Grody, N. C., and Basist, A.: An eight year (1987-1994) time series of rainfall, clouds, water vapor, 
snow cover, and sea ice derived from SSM/I measurements, B. Am. Meteor. Soc., 77, 891-905, 1996.

Gettelman, A., Liu, X., Ghan, S. J., Morrison, H., Park, S., Conley, A., Klein, S. A., Boyle, J., Mitchell, D., and Li, J.-L. F.: Global simulations of ice nucleation and ice supersaturation with an improved cloud scheme in the community atmosphere model, J. Geophys. Res., 115, D18216, doi:10.1029/2009JD013797, 2010.

Ghan, S. J., Liu, X., Easter, R. C., Zaveri, R., Rasch, P. J., Yoon, J.H., and Eaton, B.: Toward a minimal representation of aerosols in climate models: Comparative decomposition of aerosol direct, semi-direct and indirect radiative forcing. J. Climate, 25, 64616476, doi:10.1175/JCLI-D-11-00650.1, 2012.

Han, Q. Y., Rossow, W. B., and Lacis, A. A.: Near-Global survey of effective droplet radii in liquid water clouds using ISCCP data, J. Climate, 7, 465-497, 1994.

Iacono, M. J., Delamere, J. S., Mlawer, E. J., Shephard, M. W., Clough, S. A., and Collins, W. D.: Radiative forcing by long-lived greenhouse gases: calculations with the AER radiative transfer models, J. Geophys. Res.-Atmos., 113, D13103, doi:10.1029/2008jd009944, 2008.

Jokinen, T., Sipilä, M., Junninen, H., Ehn, M., Lönn, G., Hakala, J., Petäjä, T., Mauldin III, R. L., Kulmala, M., and Worsnop, D. R.: Atmospheric sulphuric acid and neutral cluster measurements using CI-APi-TOF, Atmos. Chem. Phys., 12, 4117-4125, doi:10.5194/acp-12-4117-2012, 2012.

Kazil, J. and Lovejoy, E. R.: A semi-analytical method for calculating rates of new sulfate aerosol formation from the gas phase, Atmos. Chem. Phys., 7, 3447-3459, doi:10.5194/acp-7-3447-2007, 2007.

Kazil, J., Stier, P., Zhang, K., Quaas, J., Kinne, S., O’Donnell, D., Rast, S., Esch, M., Ferrachat, S., Lohmann, U., and Feichter, J.: Aerosol nucleation and its role for clouds and Earth's radiative forcing in the aerosol-climate model ECHAM5-HAM, Atmos. Chem. Phys., 10, 10733-10752, doi:10.5194/acp-1010733-2010, 2010.

Kazil, J., Zhang, K., Stier, P., Feichter, J., Lohmann, U., and O'Brien, K.: The present-day decadal solar cycle modulation of Earth's radiative forcing via charged $\mathrm{H}_{2} \mathrm{SO}_{4} / \mathrm{H}_{2} \mathrm{O}$ aerosol nucleation, Geophys. Res. Lett., 39, L02805, doi:10.1029/2011GL050058, 2012.

Khairoutdinov, M. and Kogan, Y.: A new cloud physics parameterization in a large-eddy simulation model of marine stratocumulus, Mon. Weather Rev., 128, 229-243, 2000.

Kiehl, J. T. and Trenberth, K. E.: Earth's annual global mean energy budget, B. Am. Meteor. Soc., 78, 197-208, 1997.

Kerminen, V. M. and Kulmala, M.: Analytical formulae connecting the real and the apparent nucleation rate and the nuclei number concentration for atmospheric nucleation events, J. Aerosol Sci., 33, 609-622, doi:10.1016/S0021-8502(01)00194-X, 2002.

Kirkby, J., Curtius, J., Almeida, J., Dunne, E., Duplissy, J., Ehrhart, S., Franchin, A., Gagne, S., Ickes, L., Kuerten, A., Kupc, A., Metzger, A., Riccobono, F., Rondo, L., Schobesberger, S., Tsagkogeorgas, G., Wimmer, D., Amorim, A., Bianchi, F., Breitenlechner, M., David, A., Dommen, J., Downard, A., Ehn, M., Flagan, R. C., Haider, S., Hansel, A., Hauser, D., Jud,W., Junninen, H., Kreissl, F., Kvashin, A., Laaksonen, A., Lehtipalo, K., Lima, J., Lovejoy, E. R., Makhmutov, V., Mathot, S., Mikkila, J., Minginette, P., Mogo, S., Nieminen, T., Onnela, A., Pereira, P., Petaja, T., Schnitzhofer, R., Seinfeld, J. H., Sipila, M., Stozhkov,
Y., Stratmann, F., Tome, A., Vanhanen, J., Viisanen, Y., Vrtala, A., Wagner, P. E., Walther, H., Weingartner, E., Wex, H., Winkler, P. M., Carslaw, K. S., Worsnop, D. R., Baltensperger, U., and Kulmala, M.: Role of sulphuric acid, ammonia and galactic cosmic rays in atmospheric aerosol nucleation, Nature, 476, 429-433, 2011.

Kooperman, G. J., Pritchard, M. S., Ghan, S. J., Sommerville, R. C. J., and Russell, L. M.: Constraining the influence of natural variability to improve estimates of global aerosol indirect effects in a nudged version of the Community Atmosphere Model 5, J. Geophys. Res., doi:10.1029/2012JD018588, in press, 2012.

Kulmala, M., Riipinen, I., Sipilä, M., Manninen, H. E., Petaja, T., Junninen, H., Dal Maso, M., Mordas, G., Mirme, A., Vana, M.,Hirsikko, A., Laakso, L., Harrison, R. M., Hanson, I., Leung, C., Lehtinen, K. E. J., and Kerminen, V.-M.: Toward direct measurement of atmospheric nucleation, Science, 318, 89-92, 2007.

Loeb, N. G., Wielicki, B. A., Doelling, D. R., Smith, G. L., Keyes, D. F., Kato, S., Manalo-Smith, N., and Wong, T.: Toward Optimal Closure of the Earth's Top-of-Atmosphere Radiation Budget, J. Climate, 22, 748-766, doi:10.1175/2008jcli2637.1, 2009.

Liu, X., Penner, J. E., Ghan, S. J., and Wang, M.: Inclusion of ice microphysics in the NCAR community atmospheric model version 3 (CAM3), J. Climate, 20, 4526-4547, 2007.

Liu, X., Easter, R. C., Ghan, S. J., Zaveri, R., Rasch, P., Shi, X., Lamarque, J.-F., Gettelman, A., Morrison, H., Vitt, F., Conley, A., Park, S., Neale, R., Hannay, C., Ekman, A. M. L., Hess, P., Mahowald, N., Collins, W., Iacono, M. J., Bretherton, C. S., Flanner, M. G., and Mitchell, D.: Toward a minimal representation of aerosols in climate models: description and evaluation in the Community Atmosphere Model CAM5, Geosci. Model Dev., 5, 709-739, doi:10.5194/gmd-5-709-2012, 2012.

Lovejoy, E. R., Curtius, J., and Froyd, K. D.: Atmospheric ioninduced nucleation of sulfuric acid and water, J. Geophys. Res. 109, D08204, doi:10.1029/2003JD004460, 2004.

Luo, G. and Yu, F.: Sensitivity of global cloud condensation nuclei concentrations to primary sulfate emission parameterizations, Atmos. Chem. Phys., 11, 1949-1959, doi:10.5194/acp-111949-2011, 2011.

Makkonen, R., Asmi, A., Korhonen, H., Kokkola, H., Järvenoja, S., Räisänen, P., Lehtinen, K. E. J., Laaksonen, A., Kerminen, V.M., Järvinen, H., Lohmann, U., Bennartz, R., Feichter, J., and Kulmala, M.: Sensitivity of aerosol concentrations and cloud properties to nucleation and secondary organic distribution in ECHAM5-HAM global circulation model, Atmos. Chem. Phys., 9, 1747-1766, doi:10.5194/acp-9-1747-2009, 2009.

Morrison, H. and A. Gettelman: A new two-moment bulk stratiform cloud microphysics scheme in the community atmosphere model, version 3 (CAM3). Part I: Description and numerical tests, J. Climate, 21, 3642-3659, doi:10.1175/2008jcli2105.1, 2008.

O’Dell, C. W., Wentz, F. J., and Bennartz, R.: Cloud Liquid Water Path from Satellite-Based Passive Microwave Observations: A New Climatology over the Global Oceans, J. Climate, 21, 17211739, 2008.

Pierce, J. R. and Adams, P. J.: Efficiency of cloud condensation nuclei formation from ultrafine particles, Atmos. Chem. Phys., 7, 1367-1379, doi:10.5194/acp-7-1367-2007, 2007.

Pierce, J. R. and Adams, P. J.: Can cosmic rays affect cloud condensation nuclei by altering new particle formation rates?, Geophys. 
Res. Lett., 36, L09820, doi:10.1029/2009GL037946, 2009.

Reiter, R.: Phenomena in Atmospheric and Environmental Electricity, Elsevier, New York, 1992.

Seethala, C. and Horváth, Á.: Global assessment of AMSR$\mathrm{E}$ and MODIS cloud liquid water path retrievals in warm oceanic clouds, J. Geophys. Res., 115, D13202, doi:10.1029/2009JD012662, 2010.

Snow-Kropla, E. J., Pierce, J. R., Westervelt, D. M., and Trivitayanurak, W.: Cosmic rays, aerosol formation and cloudcondensation nuclei: sensitivities to model uncertainties, Atmos. Chem. Phys., 11, 4001-4013, doi:10.5194/acp-11-4001-2011, 2011.

Spracklen, D. V., Carslaw, K. S., Kulmala, M., Kerminen, V.M.,Sihto, S.-L., Riipinen, I., Merikanto, J., Mann, G. W., Chipperfield, P. M., Wiedensohler, A., Birmili, W., and Lihavainen, H.: Contribution of particle formation to global cloud condensation nuclei concentrations, Geophys. Res. Lett., 35, L06808, doi:10.1029/2007GL033038, 2008.

Twomey, S.: The influence of pollution on the shortwave albedo of clouds, J. Atmos. Sci., 34, 1149-1152, 1977.

Usoskin I. G. and Kovaltsov, G. A.: Cosmic ray induced ionization in the atmosphere: Full modeling and practical applications, J. Geophys. Res., 111, D21206, doi:10.1029/2006JD007150, 2006.

Wang, M. and Penner, J. E.: Aerosol indirect forcing in a global model with particle nucleation, Atmos. Chem. Phys., 9, 239-260, doi:10.5194/acp-9-239-2009, 2009.

Wang, M., Penner, J. E., and Liu, X.: Coupled IMPACT aerosol and NCAR CAM3 model: Evaluation of predicted aerosol number and size distribution, J. Geophys. Res., 114, D06302, doi:10.1029/2008JD010459, 2009.

Wang, M., Ghan, S., Ovchinnikov, M., Liu, X., Easter, R., Kassianov, E., Qian, Y., and Morrison, H.: Aerosol indirect effects in a multi-scale aerosol-climate model PNNL-MMF, Atmos. Chem. Phys., 11, 5431-5455, doi:10.5194/acp-11-5431-2011, 2011.
Yu, F.: Ion-mediated nucleation in the atmosphere: Key controlling parameters, implications, and look-up table, J. Geophy. Res., 115, D03206, doi:10.1029/2009JD012630, 2010a.

Yu, F.: Diurnal and seasonal variations of ultrafine particle formation in anthropogenic $\mathrm{SO}_{2}$ plumes, Environ. Sci. Technol., 44, 2011-2015, doi:10.1021/es903228a, 2010b.

Yu, F. and Luo, G.: Simulation of particle size distribution with a global aerosol model: contribution of nucleation to aerosol and CCN number concentrations, Atmos. Chem. Phys., 9, 76917710, doi:10.5194/acp-9-7691-2009, 2009.

Yu, F. and Turco, R. P.: Ultrafine aerosol formation via ion-mediated nucleation, Geophys. Res. Lett., 27, 883-886, 2000.

Yu, F. and Turco, R.: Case studies of particle formation events observed in boreal forests: implications for nucleation mechanisms, Atmos. Chem. Phys., 8, 6085-6102, doi:10.5194/acp-86085-2008, 2008.

Yu, F. and Turco, R. P.: The size-dependent charge fraction of sub-3$\mathrm{nm}$ particles as a key diagnostic of competitive nucleation mechanisms under atmospheric conditions, Atmos. Chem. Phys., 11, 9451-9463, doi:10.5194/acp-11-9451-2011, 2011.

Yu, F., Luo, G., Bates, T., Anderson, B., Clarke, A., Kapustin, V., Yantosca, R., Wang, Y., and Wu, S.: Spatial distributions of particle number concentrations in the global troposphere: Simulations, observations, and implications for nucleation mechanisms, J. Geophys. Res., 115, D17205, doi:10.1029/2009JD013473, 2010.

Zhang, R., Khalizov, A. F., Wang, L., Hu, M., and Wen, X.: Nucleation and growth of nanoparticles in the atmosphere, Chem. Rev., 112, 1957-2011, doi:10.1021/cr2001756, 2012. 